\title{
BMJ Open Assessing the effects of the Spanish partial smoking ban on cardiovascular and respiratory diseases: methodological issues
}

\author{
Iñaki Galán, ${ }^{1,2}$ Lorena Simón, ${ }^{1}$ Víctor Flores, ${ }^{1}$ Cristina Ortiz, ${ }^{1}$ \\ Rafael Fernández-Cuenca, ${ }^{1,3}$ Cristina Linares, ${ }^{4}$ Elena Boldo, ${ }^{1,3,5}$ \\ María José Medrano, ${ }^{1}$ Roberto Pastor-Barriuso ${ }^{1,3}$
}

To cite: Galán I, Simón L, Flores V, et al. Assessing the effects of the Spanish partial smoking ban on cardiovascular and respiratory diseases: methodological issues. BMJ Open 2015;5:e008892. doi:10.1136/bmjopen-2015008892

- Prepublication history for this paper is available online. To view these files please visit the journal online (http://dx.doi.org/10.1136/ bmjopen-2015-008892).

Received 26 May 2015 Revised 28 August 2015 Accepted 4 September 2015

CrossMark

For numbered affiliations see end of article.

Correspondence to

Dr Iñaki Galán;

igalan@isciii.es

\section{ABSTRACT}

Objective: Recent research has assessed the impact of tobacco laws on cardiovascular and respiratory morbidity. In this study, we also examined whether the association between the implementation of the 2005 Spanish smoking ban and hospital admissions for cardiovascular and respiratory diseases varies according to the adjustment for potential confounders.

Design: Ecological time series analysis.

Setting: Residents of Madrid and Barcelona cities (Spain).

Outcome: Data on daily emergency room admissions for acute myocardial infarction, cerebrovascular disease, chronic obstructive pulmonary disease (COPD), and asthma derived from the 2003-2006 Spanish hospital admissions registry.

Methods: Changes in admission rates between 2006 and the 2003-2005 period were estimated using additive Poisson models allowing for overdispersion adjusted for secular trend in admission, seasonality, day of the week, temperature, number of flu and acute respiratory infection cases, pollution levels, tobacco consumption prevalence and, for asthma cases, pollen count.

Results: In Madrid, fully adjusted models failed to detect significant changes in hospital admission rates for any disease during the study period. In Barcelona, however, hospital admissions decreased by $10.2 \%$ (95\% Cl $3.8 \%$ to $16.1 \%$ ) for cerebrovascular diseases and by $16.0 \%$ (95\% Cl $7.0 \%$ to $24.1 \%$ ) for COPD. Substantial changes in effect estimates were observed on adjustment for linear or quadratic trend. Effect estimates for asthma-related admissions varied substantially when adjusting for pollen count in Madrid, and for seasonality and tobacco consumption in Barcelona.

Conclusions: Our results confirm that the potential impact of a smoking ban must be adjusted for the underlying secular trend. In asthma-related admissions, pollen count, seasonality and tobacco consumption must be specified in the model. The substantial variability in effects detected between the two cities of Madrid and Barcelona lends strong support for a nationwide study to assess the overall effect of a

\section{Strengths and limitations of this study}

- The analysis of the effect of smoking bans on health must be adjusted for the underlying secular trend and controlling for potential confounders.

- The variability in estimates observed across the two cities in the same country strongly suggests the need to study a larger number of regions to globally assess the impact of smoking laws on health outcomes.

- The smoking ban was implemented in all regions of Spain simultaneously; thus, we were unable to compare our results against a control population.

smoking ban in Spain and identify the causes of the observed heterogeneity.

\section{INTRODUCTION}

Secondhand smoke (SHS) exposure accounts for $0.7 \%$ of worldwide disease burden or disability-adjusted life years by increasing the risk of cardiovascular and chronic obstructive respiratory diseases, among other health problems. ${ }^{12}$

Existing evidence consistently shows that even low levels of SHS exposure are quick to adversely affect heart function, blood and vascular systems, increasing the risk for ischaemic heart disease by about $30 \% .^{3-5}$ Recent evidence now includes cerebrovascular diseases as part of the SHS disease burden as well. ${ }^{6}$ Even when support for a causal relationship between SHS and respiratory disease is inconclusive, ${ }^{1}$ a reduction in risk for such pathologies has been observed following the implementation of comprehensive smoke-free laws for reducing SHS exposure. $^{7}$ 
A review ${ }^{8}$ on the effect of smoke-free legislation concluded that these laws are effective in reducing SHS exposure; however, evidence on their impact on active tobacco consumption is limited. In January 2006, Spain implemented law 28/2005 on healthcare measures regarding tobacco consumption, ${ }^{9}$ which banned smoking at the workplace and imposed a partial ban on restaurants, bars and any establishment serving food and/or beverages. This law achieved a substantial reduction in SHS exposure in the workplace but with little impact on exposure at restaurants, bars and similar venues. ${ }^{10-12}$

Many studies have assessed the impact of regulations to prevent SHS exposure, including the impact on hospital admissions for cardiovascular and respiratory diseases. ${ }^{7}{ }^{13-27}$ Although most are based on time-series analysis, many fail to account for potentially confounding variables and estimates are highly sensitive to adjustment for the non-linearity in secular trend. ${ }^{28} 29$

Our main aim is to assess the impact of smoke-free legislation on cardiovascular and respiratory morbidity in two large Spanish cities while ascertaining the effect of potential confounders. Results will inform the analytical plan of data provided by other regions in Spain.

\section{METHODS}

\section{Study population}

Our study population consists of all the residents of Madrid and Barcelona with an average population size during the study period of 3124090 and 1591529 inhabitants, respectively. Data were compiled from hospital admission records from the Basic Minimum Set of Data (BMSD) from January 2003 to December 2006. This data set records admissions to hospitals included in the National Healthcare System, both public hospitals and private ones within the consortium. We analysed the number of daily emergency admissions for acute myocardial infarction as the primary diagnosis, except for ensuing episodes (International Classification of Diseases, ICD 9, 410.x.0 and 410.x.1) in those 18 years of age and older; cerebrovascular disease (ICD 9, 430438 ) in those 18 years of age and older; chronic obstructive pulmonary disease (COPD) (ICD 9, 490492; 494-496) in those at least 40 years of age; and asthma (ICD 9, 493) regardless of age.

To guarantee the confidentiality of the patients, the information of clinical records was anonymised and de-identified prior to analysis.

\section{Analysis}

Changes in hospital admission rates during the first year of the smoking ban were estimated using an indicator variable for the year 2006 in additive Poisson with overdispersion. The long-term secular trend was adjusted by including a homogeneous linear term all along the day series. If significant deviations from linearity were detected during the time period preceding the smoking ban, a quadratic term was also included in the series.
Seasonality was modelled using harmonic terms and indicator variables for the days of the week. We adjusted for the following potential confounders (data source): maximum daily temperature (National Institute of Meteorology), including up to seven time lags; number of flu cases (Sentinel Physician Network of the Influenza Surveillance System in Spain): the weekly datum was interpolated as a daily value, including up to 10 time lags; daily emergency hospital admissions (BMSD) for acute respiratory infections, with up to 10 time lags. Air pollution was assessed on the basis of daily pollutant levels using $24 \mathrm{~h}$ averages $\left(\mu \mathrm{g} / \mathrm{m}^{3}\right)$ of $\mathrm{SO}_{2}$, particulate matter $\left(\mathrm{PM}_{10}\right)$ and $\mathrm{NO}_{2}$ and the maximum value for the $8 \mathrm{~h}$ average for $\mathrm{O}_{3}$. We examined five time lags for $\mathrm{SO}_{2}$, four lags for $\mathrm{PM}_{10}$ and $\mathrm{NO}_{2}$, and nine lags for $\mathrm{O}_{3}$. Pollen data were included when examining admissions due to asthma. The variable pollen was estimated on the basis of the daily count (grains $/ \mathrm{m}^{3}$ ) of Poaceae, Plantago, Olea and Urticaceae and up to four time lags for pollen were included. We also adjusted for the percentage of the population over 16 years of age consuming tobacco with any frequency. Data came from the 2003 and 2006 National Health Surveys. Tobacco consumption data from 2003 were applied to years 2003 and 2004 and tobacco data from 2006 were applied to years 2005 and 2006, adjusting for population size at the time. Temperature, air pollution and pollen count variables were included in the model using smoothing splines with up to four degrees of freedom.

We ran sequential models to examine changes in coefficients according to levels of adjustment (each model builds on the previous one): (1) basic model with no adjustment; (2) adjusting for long-term trend; (3) adjusting for seasonality and controlling for the day of the week, flu and acute respiratory infections; (4) controlling for air pollution and (5) finally, the complete model also controls for tobacco consumption. For asthma cases, we also ran a model to assess the potential confounding effect of pollen count on the association between the smoking ban and hospital admissions for asthma.

\section{RESULTS}

Table 1 shows crude hospital admission rates (per thousand inhabitants) for each study year. Table 2 shows these rate distributions for each of the daily series, as well as the distribution of the study covariates. Barcelona reported greater rates of cardiovascular diseases and COPD and Madrid reported more cases of asthma. During the period preceding the smoking ban (20032005) series trends are linear, for the most part, except for COPD for which we observe a statistically significant quadratic trend in both cities (table 1 and figure 1). Figure 1 shows seasonal patterns with highs during winter months and lows during the summer; these patterns are especially pronounced for COPD and, to a lesser extent, for myocardial infarction. Asthma in Madrid experiences an increase during the months of 
Table 1 Hospital admissions for cardiovascular and respiratory diseases

\begin{tabular}{|c|c|c|c|c|c|c|c|c|c|c|}
\hline & \multicolumn{2}{|l|}{2003} & \multicolumn{2}{|l|}{2004} & \multicolumn{2}{|l|}{2005} & \multicolumn{2}{|c|}{ 2003-2005 Trend } & \multicolumn{2}{|l|}{2006} \\
\hline & $\mathbf{N}$ & $\begin{array}{l}\text { Rate per } \\
1000\end{array}$ & $\mathbf{N}$ & $\begin{array}{l}\text { Rate per } \\
1000\end{array}$ & $\mathbf{N}$ & $\begin{array}{l}\text { Rate per } \\
1000\end{array}$ & $\begin{array}{l}\text { Linear } \\
\text { p value }\end{array}$ & $\begin{array}{l}\text { Quadratic } \\
\text { p value }\end{array}$ & $\mathbf{N}$ & $\begin{array}{l}\text { Rate per } \\
1000\end{array}$ \\
\hline \multicolumn{11}{|l|}{ Madrid } \\
\hline Myocardial infarction & 2528 & 0.96 & 2483 & 0.94 & 2431 & 0.91 & 0.093 & 0.981 & 2431 & 0.92 \\
\hline Cerebrovascular disease & 4045 & 1.50 & 4130 & 1.56 & 4368 & 1.64 & 0.002 & 0.297 & 4297 & 1.62 \\
\hline COPD & 4319 & 2.68 & 4203 & 2.86 & 4478 & 3.38 & 0.665 & 0.014 & 3515 & 2.97 \\
\hline Asthma & 1054 & 0.34 & 1114 & 0.36 & 1145 & 0.36 & 0.111 & 0.760 & 1399 & 0.45 \\
\hline \multicolumn{11}{|l|}{ Barcelona } \\
\hline Myocardial infarction & 1843 & 1.36 & 1938 & 1.42 & 1847 & 1.35 & 0.756 & 0.074 & 1726 & 1.26 \\
\hline Cerebrovascular disease & 3075 & 2.27 & 3305 & 2.43 & 3395 & 2.47 & 0.001 & 0.235 & 3208 & 2.34 \\
\hline COPD & 4545 & 5.47 & 4207 & 5.04 & 4371 & 5.19 & 0.012 & 0.003 & 2817 & 3.33 \\
\hline Asthma & 298 & 0.19 & 330 & 0.21 & 302 & 0.19 & 0.989 & 0.153 & 235 & 0.15 \\
\hline
\end{tabular}

May and June and again in September, whereas seasonality is not as easy to spot in Barcelona. Cerebrovascular disease does not reveal a seasonal pattern.

Table 3 shows the effects of the ban on admissions for cardiovascular diseases according to models with sequential adjustment for potential confounders. Results are expressed as a change in percentage of admissions reported in 2006 compared to those reported during the 2003-2005 period. On the basis of the fully adjusted model (model E), admissions in Madrid for acute myocardial infarction experienced a non-significant increase of $6.6 \%$ (95\% CI $-1.5 \%$ to $15.5 \%$ ) and, in Barcelona, a non-significant decrease of $-6.3 \%$ (95\% CI $-14.7 \%$ to $2.9 \%)$. The greatest change in estimate in both cities was observed when we controlled for trend. Sequential adjustment for seasonality and related variables, pollution and tobacco consumption does not have a substantial effect on the estimates. Regarding cerebrovascular disease, whereas the fully adjusted model (model E) for Madrid reveals no association, results for Barcelona point to a statistically significant decrease in admissions of over $10 \%$ associated with the implementation of the smoking ban $-3.8 \%$ : $(-10.2 \%$ (95\% CI $-16.1 \%$ to $-3.8 \%))$. As described above, the greatest change in estimates is observed in both cities when the association is adjusted for trend.

Table 4 shows the effects of the ban on admissions for respiratory diseases according to models with sequential adjustment for potential confounders. Fully adjusted estimates, including for linear trend (model E), indicate a statistically significant reduction of $16 \%$ in hospital admissions for COPD in Madrid (95\% CI $-21.6 \%$ to

Table 2 Distribution of study variables (daily values)

\begin{tabular}{|c|c|c|c|c|c|c|c|c|c|c|c|c|}
\hline & \multicolumn{6}{|l|}{ Madrid } & \multicolumn{6}{|l|}{ Barcelona } \\
\hline & Mean (SD) & $\mathbf{P}_{5}{ }^{*}$ & $\mathbf{P}_{25}$ & $\mathbf{P}_{50}$ & $\mathbf{P}_{75}$ & $\mathbf{P}_{95}$ & Mean (SD) & $\mathbf{P}_{5}$ & $\mathbf{P}_{25}$ & $P_{50}$ & $P_{75}$ & $P_{95}$ \\
\hline Myocardial infarction, n & $13.5(4.5)$ & 7 & 10 & 13 & 16 & 21 & $9.7(3.4)$ & 4 & 7 & 9 & 12 & 15 \\
\hline $\begin{array}{l}\text { Cerebrovascular } \\
\text { disease, } n\end{array}$ & $11.5(3.8)$ & 6 & 9 & 11 & 14 & 18 & $8.9(3.1)$ & 4 & 7 & 9 & 11 & 14 \\
\hline COPD†, $\mathrm{n}$ & $11.3(5.8)$ & 4 & 7 & 10 & 14 & 22 & $10.9(5.7)$ & 4 & 7 & 10 & 10 & 22 \\
\hline Asthma, $\mathrm{n}$ & $3.3(2.3)$ & 0 & 1 & 3 & 5 & 7 & $0.8(1.0)$ & 0 & 0 & 1 & 1 & 3 \\
\hline Flu, $n$ & 366 (622) & 7 & 27 & 106 & 343 & 1650 & $138(248)$ & 9 & 21 & 55 & 141 & 541 \\
\hline $\begin{array}{l}\text { Acute respiratory } \\
\text { infections, } \mathrm{n}\end{array}$ & $5.2(4.8)$ & 0 & 2 & 4 & 7 & 16 & $8.3(5.5)$ & 2 & 5 & 7 & 11 & 18 \\
\hline Temperature, ${ }^{\circ} \mathrm{C}$ & $20.4(9)$ & 7.8 & 12.4 & 18.3 & 28 & 34.2 & $19.8(7.6)$ & 8.4 & 13.4 & 19.5 & 26.1 & 32 \\
\hline $\mathrm{PM}_{10}, 24 \mathrm{~h} \mu \mathrm{g} \mathrm{m}$ & $36.9(18.7)$ & 13.6 & 22 & 34.1 & 47.3 & 72.1 & $40.5(15.8)$ & 19 & 29.6 & 38.5 & 49.2 & 68.5 \\
\hline $\mathrm{SO}_{2}, 24 \mathrm{~h} \mu \mathrm{g} \mathrm{m}^{3}$ & $12.6(6.2)$ & 6.8 & 8.3 & 10.2 & 15.1 & 26.2 & $3.8(3.5)$ & 1 & 1.1 & 2.4 & 5 & 10.9 \\
\hline $\mathrm{NO}_{2}, 24 \mathrm{~h} \mu \mathrm{g} \mathrm{m}$ & $60.7(18.6)$ & 34.1 & 47 & 58.5 & 71.9 & 96.1 & $73.4(23.4)$ & 39 & 55.4 & 71.9 & 89.1 & 114.5 \\
\hline $\mathrm{O}_{3}, 8 \mathrm{~h} \mu \mathrm{g} \mathrm{m}$ & $52.9(27.1)$ & 11.5 & 31.1 & 52.7 & 72.2 & 98.2 & $43.5(26.3)$ & 8 & 23 & 39 & 60 & 94 \\
\hline Poaceae, grains $/ \mathrm{m}^{3}$ & $4.3(16.4)$ & 0 & 0 & 1 & 3 & 18 & $3(7.5)$ & 0 & 0 & 0.7 & 2.1 & 16.1 \\
\hline Plantago, grains $/ \mathrm{m}^{3}$ & $0.8(2.8)$ & 0 & 0 & 0 & 0 & 4.9 & 0.9 (1.9) & 0 & 0 & 0 & 0.7 & 4.9 \\
\hline Olea, grains $/ \mathrm{m}^{3}$ & $2.9(21.1)$ & 0 & 0 & 0 & 0 & 10 & $3.3(13.5)$ & 0 & 0 & 0 & 0.7 & 19.5 \\
\hline Urticaceae, grains $/ \mathrm{m}^{3}$ & $0.8(2.1)$ & 0 & 0 & 0 & 1 & 4 & $5.1(7.9)$ & 0 & 0.7 & 2.1 & 5.6 & 21.7 \\
\hline
\end{tabular}


Madrid
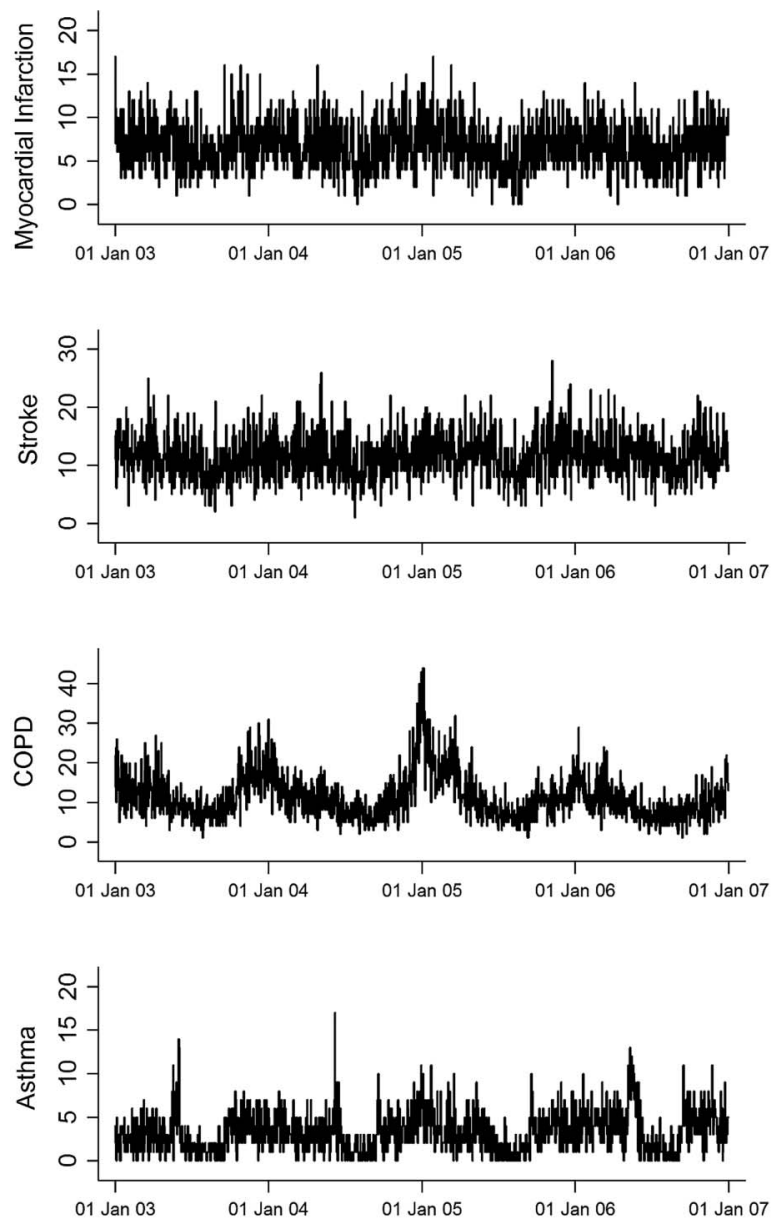

Barcelona
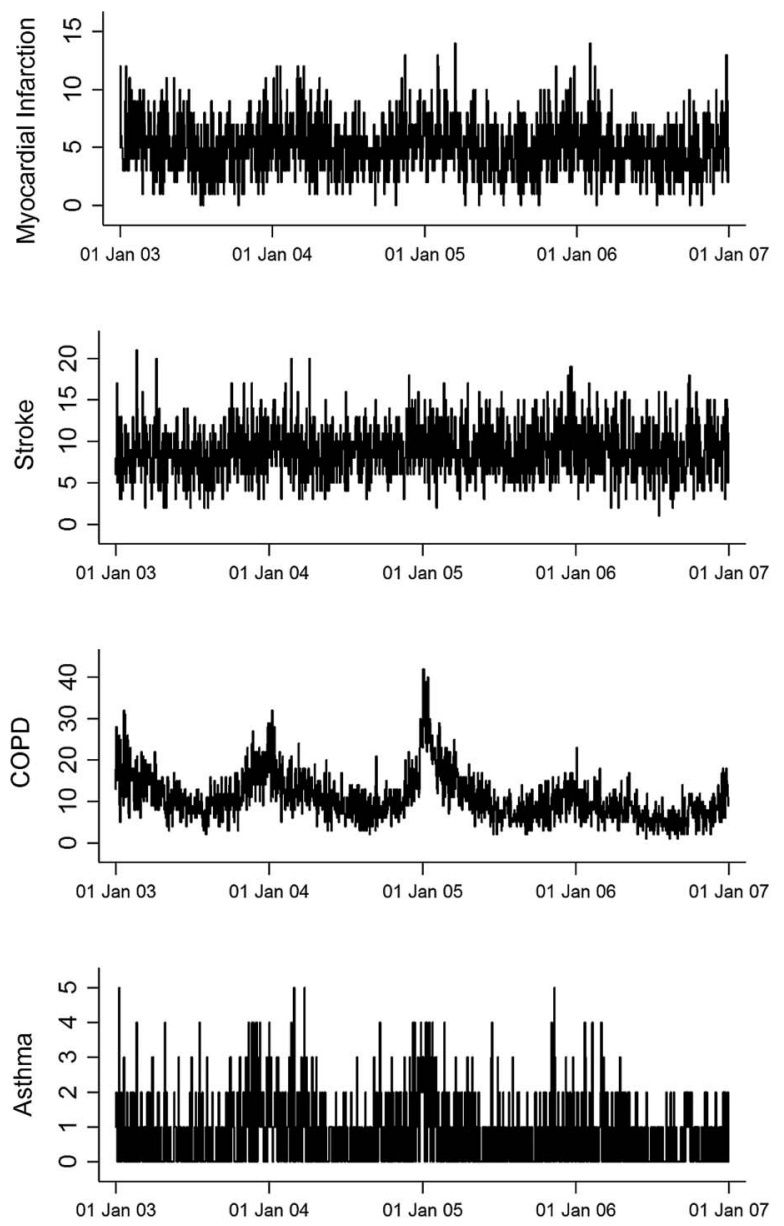

Figure 1 Per day hospital admissions for cardiovascular and respiratory diseases in Madrid and Barcelona (Spain), 2003-2006 period (COPD, chronic obstructive pulmonary disease).

$-9.9 \%)$ and a reduction of $21.1 \%$ in Barcelona $(95 \%$ CI $-26.3 \%$ to $-15.5 \%)$. In both cities, admission rates for COPD dropped substantially after adjusting for trend but saw little variation when adjusted for the remaining variables. In Barcelona, however, there was a moderate reduction in admissions on adjustment for seasonality. Modelling a quadratic trend (table 4, model F) explains away the observed reductions in Madrid and yields a nonsignificant $2.5 \%$ (95\% CI $-7.4 \%$ to $13.6 \%$ ) increase in admissions. In contrast, in Barcelona, a reduction of $16 \%$, though smaller than when correcting for linear trend, remains statistically significant ( $95 \%$ CI -24.1 to $-7.0 \%$ ).

Regarding asthma, fully adjusted models point to nonstatistically significant changes in admission rates in both cities but in opposite directions. Admissions in Madrid experienced an increase of $10.5 \%(95 \%$ CI $-2.9 \%$ to $25.7 \%$ ), whereas in Barcelona hospital admissions dropped by $15.4 \%$ (95\% CI $-34.0 \%$ to $8.4 \%$ ). In Madrid, accounting for pollen count substantially affects the estimates, whereas in Barcelona, seasonality and tobacco consumption turn out to be the confounders with the most effect on the association between smoking ban and hospital admissions for asthma.
Table 3 Percentage rate change in hospital admissions for myocardial infarction and cerebrovascular disease in 2006 versus the 2003-2005 period in Madrid and Barcelona (Spain)

\begin{tabular}{|c|c|c|}
\hline & \multicolumn{2}{|c|}{ Percentage change $(95 \% \mathrm{Cl})$} \\
\hline & Madrid & Barcelona \\
\hline \multicolumn{3}{|c|}{ Myocardial infarction } \\
\hline Model A & $-1.9(-6.7$ to 3.1$)$ & $-8.6(-13.7$ to -3.3$)$ \\
\hline Model B & $4.5(-3.1$ to 12.7$)$ & $-4.5(-12.5$ to 4.2$)$ \\
\hline Model C & $5.2(-2.3$ to 13.4$)$ & $-6.5(-14.5$ to 2.2$)$ \\
\hline Model D & $6.3(-1.4$ to 14.5$)$ & $-3.8(-12.2$ to 5.3$)$ \\
\hline Model E & $6.6(-1.5$ to 15.5$)$ & $-6.3(-14.7$ to 2.9$)$ \\
\hline \multicolumn{3}{|c|}{ Cerebrovascular disease } \\
\hline Model A & $2.9(-1.1$ to 7.0$)$ & $-2.2(-6.2$ to 2.0$)$ \\
\hline Model B & $-0.4(-6.1$ to 5.7$)$ & $-9.1(-14.6$ to -3.2$)$ \\
\hline Model C & $-1.5(-6.9$ to 4.3$)$ & $-9.1(-14.8$ to -3.0$)$ \\
\hline Model D & $-1.5(-6.9$ to 4.3$)$ & $-9.6(-15.3$ to -3.5$)$ \\
\hline Model E & $0.8(-5.2$ to 7.1$)$ & $-10.2(-16.1$ to -3.8$)$ \\
\hline \multicolumn{3}{|c|}{$\begin{array}{l}\text { Model A, basic model, unadjusted; model B, adjusted for linear } \\
\text { secular trend; model C, additional adjustment for seasonality, day } \\
\text { of the week, temperature, flue and acute respiratory infections; } \\
\text { model D, additional adjustment for pollution levels; model E, } \\
\text { additional adjustment for tobacco consumption prevalence. }\end{array}$} \\
\hline
\end{tabular}


Table 4 Percentage rate change in hospital admissions for chronic obstructive pulmonary disease and asthma in 2006 versus the 2003-2005 period in Madrid and Barcelona (Spain)

\begin{tabular}{ccc}
\hline & \multicolumn{2}{l}{ Percentage change $(95 \% \mathrm{Cl})$} \\
\cline { 2 - 3 } & Madrid & Barcelona \\
\hline COPD & & \\
Model A & $-20.4(-25.1$ to -15.5$)$ & $-36.3(-40.2$ to -32.2$)$ \\
Model B & $-14.5(-21.7$ to -6.6$)$ & $-24.6(-30.9$ to -17.7$)$ \\
Model C & $-15.6(-21.0$ to -9.9$)$ & $-21.1(-26.1$ to -15.7$)$ \\
Model D & $-15.8(-21.2$ to -10.1$)$ & $-20.7(-25.8$ to -15.3$)$ \\
Model E & $-16.0(-21.6$ to -9.9$)$ & $-21.1(-26.3$ to -15.5$)$ \\
Model F & $2.5(-7.4$ to 13.6$)$ & $-16.0(-24.1$ to -7.0$)$ \\
Asthma & & \\
Model A & $26.5(16.4$ to 37.4$)$ & $-24.7(-35.8$ to -11.7$)$ \\
Model B & $20.0(5.3$ to 36.7$)$ & $-19.8(-36.2$ to 0.8$)$ \\
Model C & $24.2(9.9$ to 40.2$)$ & $-9.2(-28.4$ to 15.2$)$ \\
Model D & $27.0(12.4$ to 43.5$)$ & $-9.8(-29.0$ to 14.6$)$ \\
Model E & $11.2(-1.5$ to 25.5$)$ & $-10.2(-29.3$ to 14.0$)$ \\
Model F & $10.5(-2.9$ to 25.7$)$ & $-15.4(-34.0$ to 8.4$)$ \\
\hline
\end{tabular}

COPD (chronic obstructive pulmonary disease): model $\mathrm{A}$, basic model, unadjusted; model B, adjusted for linear secular trend; model C, additional adjustment for seasonality, day of the week, temperature, flue and acute respiratory infections; model D, additional adjustment for pollution levels; model $\mathrm{E}$, additional adjustment for tobacco consumption prevalence; model $\mathrm{F}$, full model adjusted for quadratic secular trend.

Asthma: model A, basic model, unadjusted; model B, adjusted for linear secular trend; model $\mathrm{C}$, additional adjustment for seasonality, day of the week, temperature, flue and acute respiratory infections; model $\mathrm{D}$, additional adjustment for pollution levels; model $\mathrm{E}$, additional adjustment for pollen count; model $\mathrm{F}$, additional adjustment for tobacco consumption prevalence.

\section{DISCUSSION}

Both cities experienced reductions in hospital admissions for COPD during the first year of the smoking ban implementation. Estimates remained statistically significant even after adjusting for linear trend; however, adjusting for quadratic trend renders the estimate for Madrid non-significant. Similarly, admissions for cerebrovascular diseases in Barcelona decreased significantly. No effects of the smoking ban on admissions for acute myocardial infarction or asthma were detected. Our sequential models suggest that results are sensitive to trend adjustment and that the influence of other covariates on the main association varies by disease and city of interest.

The moderate effect of the smoking ban on the prevention of hospital admissions for cardiovascular diseases observed in our study is consistent with the literature suggesting that benefits are observed mainly on regions with comprehensive smoking laws banning smoking at the workplace as well as in bars and restaurants. ${ }^{7}$ Regions and countries where preventing SHS exposure is limited to the workplace failed to observe any benefits ${ }^{14} 30$ or were very limited. ${ }^{21}$ Two studies in Spain with a 'pre-post' design detected positive effects of the smoking ban on hospital admissions for myocardial infarction. The first one, performed in Barcelona between 2004 and 2006, ${ }^{23}$ detected an acceleration of the annual reduction close to $5 \%$ in men and $2 \%$ in women, similar to our trend-adjusted results $(4.5 \%)$. The second study, carried out in the province of Girona on the basis of data from the REGICOR study, ${ }^{24}$ estimated a $11 \%$ decrease in hospital admission risk for myocardial infarction in 20062008 compared to 2002-2005.

Numerous previous studies have assessed the effect of SHS exposure regulations on hospital admissions, but few of them have controlled for potential confounding variables. In time series studies, variables such as air pollution, temperature or flu cases, which may vary along the study period, are associated with both cardiovascular and respiratory diseases. ${ }^{31} 32$ Only three studies included temperature and flu cases ${ }^{17} 33$ and two also accounted for atmospheric pollution (particles). ${ }^{17} 34$ In our results, the effect of these variables is small, probably reflecting the short study period, which limits data variability. An exception is the COPD epidemic peak of 2005, which may have been related to the large flu epidemic of the same year. ${ }^{35}$ This variable is the main reason for the moderate adjustment when controlling for seasonality in the Barcelona model (model $\mathrm{C}$ ), which slightly reduced the size of the beneficial effect associated with the smoking ban.

When it comes to evaluating the impact of regulations on health outcomes, a key methodological issue regarding model specification is the assumption of either a linear or quadratic trend. Although some studies do not adjust for underlying trend, most of them do adjust for a linear one. However, two studies showed a change in estimates when the trend was modelled as non-linear. Gasparrini et $a l^{29}$ compared results from a statistical model with a quadratic term versus one with a linear term only to witness the previously observed protective effect of the ban on hospital admissions for myocardial infarction in a region of Italy disappear. Barr et $a l^{28}$ reran analyses on data from 387 US counties and also observed how the effects of the smoking ban on hospital admissions for myocardial infarction were dampened until the risk estimate equalled 0 after modelling non-linear terms based on cubic splines with different degrees of freedom. Non-linear adjustment may be of particular importance when the number of years in the series is large, as the probability of detecting non-linear trends increases with the number of years under study. In our work, we only observed a quadratic trend in the years before the smoking ban for COPD, and this is very likely due to the COPD increase due to the $2005 \mathrm{flu}$. As in previous studies, modelling a quadratic trend rendered the possible ban effect in Madrid null and reduced the magnitude of the effect in Barcelona. Nonetheless, modelling non-linear terms remains controversial due to the high probability of capturing the very own regulation effect, to the point of making it disappear.

Tobacco consumption is another important variable to examine in this context because it is related to both the regulation as well as to its effect. On the one hand, it is 
a greater risk factor than SHS exposure. On the other hand, its prevalence and intensity are positively correlated with SHS exposure. In addition, a smoking ban may have a beneficial effect on tobacco consumption prevalence and the number of cigarettes smoked as observed in Italy, ${ }^{36}$ and with the increase in ex-smokers in England. ${ }^{37}$ In Spain, smoking prevalence, slightly decreasing both in men and women, has not been affected by the ban, similar to what has been observed in countries around us. ${ }^{88}$ The ban's effect on estimates, except for the change in hospitalisations for asthma in Barcelona, is moderate overall. This could be due in part to the trend variable itself, which captures timerelated variations in risk factors or protective factors, masking part of the ban's effect on hospital admissions.

Another consideration is the variability between regions of similar geographic characteristics where the regulation is implemented. We observed variability in the results reported from the two cities under study; further, in some estimates, variability is greater than the one expected due to chance. Sources of this heterogeneity are not clear but they may be related to the actual implementation. Madrid is the region with the highest number of police report filings for smoking ban violations (weighed by population size), whereas Catalonia, the region encompassing the city of Barcelona, is among the regions with the lowest filings. There were four more reports filed in Madrid than in Catalonia and four times as many fines imposed per number of inspected venues. ${ }^{39}$ This variability between regions has been highlighted by Shetty $e t a \hat{l}^{0}$ who showed that positive and negative changes in acute myocardial infarction incidence were equally likely after a smoking ban in the USA and comparisons of small samples might have led to atypical findings.

SHS prevention has unambiguously beneficial effects on several health outcomes. However, policy evaluation reveals that a statewide ban on smoking in public places would have drawn atypical conclusions depending on the condition selected. These results reinforce the need to test multiple outcomes, and the evaluation should consider systematic approaches to account for the issues, including alternative model specifications and sensitivity analyses. ${ }^{40}$ In our study, several sensitivity analyses have been run testing different ways to control for the potential confounders. For instance, we examined three flu indicators and tobacco consumption was also assessed using cigarette sales. We also reanalysed the data using only incident cases, eliminating hospital readmissions for the same disease based on the identification of the case by sex, birth date and province of residence. Results did not vary significantly. Additional variables potentially related to hospital admissions for cardiovascular diseases, such as consumption of statins, antidiabetic drugs and antihypertensive drugs, were not included in the analyses given that their lineal or exponential consumption pattern growth destabilised our parameters for trend or tobacco consumption. ${ }^{41}$ Their effect, however, is very likely captured indirectly in the term for trend in the time series.

Our results should be interpreted taking into account the following limitations. First, causality cannot be inferred given the ecological nature of the study. Second, the characteristics of hospital admissions registry did not allow the collection of individual information such as tobacco consumption. Third, despite adjusting for important covariates, changes in other factors not controlled for here may have influenced our results. Similarly, although our time series include only a few years, we cannot ignore the possibility of administrative changes related to the registry associated with the hospitalisation of the diseases of interest. Finally, since the smoking ban was implemented in all regions of Spain simultaneously, there is no control population to compare our results against.

Among the strengths of the study, the two main ones are that the data came from large samples of two large metropolitan cities and that we were able to include many covariates with objective measures taken at the local level, not examined in the most previous studies.

To conclude, the potential impact of the smoking ban must be adjusted for the underlying secular trend, in addition to pollen count, seasonality and tobacco consumption in the case of hospital admissions for asthma. The variability in estimates observed across the two cities in the same country strongly suggests the need to study a larger number of regions to globally assess the impact of smoking. The Spanish partial smoking ban was effective in reducing SHS exposure at the workplace, while having no impact on active tobacco consumption, and so far the results on cardiovascular and respiratory morbidity have proven inconsistent. A future evaluation of the second ban implemented in January 2011, prohibiting smoking in all public places, will help us elucidate the global impact of a comprehensive smoke-free policy on health outcomes.

\section{Author affiliations}

${ }^{1}$ National Centre for Epidemiology, Instituto de Salud Carlos III, Madrid, Spain ${ }^{2}$ Department of Preventive Medicine and Public Health, School of Medicine, Universidad Autónoma de Madrid/IdiPAZ, Madrid, Spain

${ }^{3}$ CIBER de Epidemiología y Salud Pública (CIBERESP), Madrid, Spain

${ }^{4}$ National School of Public Health, Instituto de Salud Carlos III, Madrid, Spain

${ }^{5}$ Puerta de Hierro Biomedical Research Institute, Madrid, Spain

Acknowledgements The authors would like to thank Amparo Larrauri (Spanish Influenza Sentinel Surveillance System) for providing data about Influenza, Xavier Querol (Centro Superior de Investigaciones Científicas, Barcelona) for $\mathrm{PM}_{10}$ of Barcelona, and Jordina Belmonte (Xarxa Aerobiològica de Catalunya) and Montserrat Gutiérrez Bustillo (Red PALINOCAM, Madrid) for pollen information.

Contributors IG was responsible for the study conception and design. LS, $\mathrm{CO}, \mathrm{VF}$ and RP-B provided input into design and analysed the data. RF-C, $\mathrm{CL}$, $\mathrm{EB}$ and MJM contributed to the analysis. IG, RP-B, EB, CL and MJM wrote the paper and prepared the manuscript. All the authors reviewed and approved the final version.

Funding This work was supported by grant FIS PI11/01276 from the Institute of Health Carlos III, Ministry of Economy and Competitiveness. 
Competing interests None declared.

Ethics approval This study was approved by the Institutional Review Board of the Carlos III Institute of Health.

Provenance and peer review Not commissioned; externally peer reviewed.

Data sharing statement No additional data are available.

Open Access This is an Open Access article distributed in accordance with the Creative Commons Attribution Non Commercial (CC BY-NC 4.0) license, which permits others to distribute, remix, adapt, build upon this work noncommercially, and license their derivative works on different terms, provided the original work is properly cited and the use is non-commercial. See: http:// creativecommons.org/licenses/by-nc/4.0/

\section{REFERENCES}

1. US Surgeon General. The health consequences of involuntary exposure to tobacco smoke: a report of the surgeon general. Atlanta US Department of Health and Human Services, Centers for Disease Control and Prevention, Coordinating Center for Health Promotion, National Center for Chronic Disease Prevention and Health Promotion, Office on Smoking and Health, 2006.

2. Oberg M, Jaakkola MS, Woodward A, et al. Worldwide burden of disease from exposure to second-hand smoke: a retrospective analysis of data from 192 countries. Lancet 2011;377:139-46.

3. Barnoya J, Glantz SA. Cardiovascular effects of secondhand smoke: nearly as large as smoking. Circulation 2005;111:2684-98.

4. Faught BE, Flouris AD, Cairney J. Epidemiological evidence associating secondhand smoke exposure with cardiovascular disease. Inflamm Allergy Drug Targets 2009;8:321-7.

5. Vardavas $\mathrm{Cl}$, Panagiotakos DB. The causal relationship between passive smoking and inflammation on the development of cardiovascular disease: a review of the evidence. Inflamm Allergy Drug Targets 2009;8:328-33.

6. Oono IP, Mackay DF, Pell JP. Meta-analysis of the association between secondhand smoke exposure and stroke. J Public Health (Oxf) 2011;33:496-502.

7. Tan CE, Glantz SA. Association between smoke-free legislation and hospitalizations for cardiac, cerebrovascular, and respiratory diseases: a meta-analysis. Circulation 2012;126:2177-83.

8. Callinan JE, Clarke A, Doherty $\mathrm{K}$, et al. Legislative smoking bans for reducing secondhand smoke exposure, smoking prevalence and tobacco consumption. Cochrane Database Syst Rev 2010;(4): CD005992.

9. Ley de medidas sanitarias frente al tabaquismo y reguladora de la venta, el suministro y la publicidad de los productos del tabaco. L. N 28/2005 (27 diciembre 2005). http://www.boe.es/boe/dias/2005/12/ 27/pdfs/A42241-42250.pdf (accessed 15 May 2015).

10. Galán I, Mata N, Estrada C, et al. Impact of the "Tobacco control law" on exposure to environmental tobacco smoke in Spain. BMC Public Health 2007;7:224.

11. Jiménez-Ruiz CA, Miranda JA, Hurt RD, et al. Study of the impact of laws regulating tobacco consumption on the prevalence of passive smoking in Spain. Eur J Public Health 2008;18:622-5.

12. Pérez-Ríos M, Santiago-Pérez MI, Malvar A et al. Impact of the Spanish smoking laws on the exposure to environmental tobacco smoke in Galicia (2005-2011). Gac Sanit 2014;28:20-4.

13. Lin $\mathrm{H}$, Wang $\mathrm{H}$, Wu W, et al. The effects of smoke-free legislation on acute myocardial infarction: a systematic review and meta-analysis. BMC Public Health 2013;13:529.

14. Naiman A, Glazier $\mathrm{RH}$, Moineddin R. Association of anti-smoking legislation with rates of hospital admission for cardiovascular and respiratory conditions. CMAJ 2010;182:761-7.

15. Gaudreau K, Sanford CJ, Cheverie C, et al. The effect of a smoking ban on hospitalization rates for cardiovascular and respiratory conditions in Prince Edward Island, Canada. PLoS ONE 2013;8: e56102.

16. Barone-Adesi F, Gasparrini A, Vizzini L, et al. Effects of Italian smoking regulation on rates of hospital admission for acute coronary events: a country-wide study. PLOS ONE 2011;6:e17419.

17. Sims M, Maxwell R, Bauld L, et al. Short term impact of smoke-free legislation in England: retrospective analysis of hospital admissions for myocardial infarction. BMJ 2010;340:c2161.

18. Pell JP, Haw S, Cobbe S, et al. Smoke-free legislation and hospitalizations for acute coronary syndrome. N Engl J Med 2008;359:482-91.
19. Sargent JD, Demidenko E, Malenka DJ, et al. Smoking restrictions and hospitalization for acute coronary events in Germany. Clin Res Cardiol 2012;101:227-35.

20. Cronin EM, Kearney PM, Kearney PP, et al. Impact of a national smoking ban on hospital admission for acute coronary syndromes: a longitudinal study. Clin Cardiol 2012;35:205-9.

21. Ferrante D, Linetzky B, Virgolini M, et al. Reduction in hospital admissions for acute coronary syndrome after the successful implementation of $100 \%$ smoke-free legislation in Argentina: a comparison with partial smoking restrictions. Tob Control 2012;21:402-6.

22. Sebrié EM, Sandoya E, Hyland A, et al. Hospital admissions for acute myocardial infarction before and after implementation of a comprehensive smoke-free policy in Uruguay. Tob Control 2013;22: e16-20.

23. Villalbi JR, Castillo A, Cleries M, et al. Acute myocardial infarction hospitalization statistics: apparent decline accompanying an increase in smoke-free areas. Rev Esp Cardiol 2009;62:812-5.

24. Agüero F, Dégano IR, Subirana I, et al. Impact of a partial smoke-free legislation on myocardial infarction incidence, mortality and case-fatality in a population-based registry: the REGICOR Study. PLOS ONE 2013;8:e53722.

25. Hahn EJ, Rayens MK, Adkins S, et al. Fewer hospitalizations for chronic obstructive pulmonary disease in communities with smoke-free public policies. Am J Public Health 2014;104:1059-65.

26. Mackay D, Haw S, Ayres JG, et al. Smoke-free legislation and hospitalizations for childhood asthma. $N$ Engl J Med 2010;363:1139-45.

27. Rayens MK, Burkhart PV, Zhang M, et al. Reduction in asthma-related emergency department visits after implementation of a smoke-free law. J Allergy Clin Immunol 2008;122:537-41.

28. Barr CD, Diez DM, Wang Y, et al. Comprehensive smoking bans and acute myocardial infarction among Medicare enrollees in 387 US counties: 1999-2008. Am J Epidemiol 2012;176:642-8.

29. Gasparrini A, Gorini G, Barchielli A. On the relationship between smoking bans and incidence of acute myocardial infarction. Eur J Epidemiol 2009;24:597-602.

30. Shetty KD, DeLeire T, White $C$, et al. Changes in U.S. hospitalization and mortality rates following smoking bans. J Policy Anal Manage 2010;30:6-28.

31. Ballester F, Rodríguez $P$, Iñiguez $C$, et al. Air pollution and cardiovascular admissions association in Spain: results within the EMECAS project. J Epidemiol Community Health 2006;60:328-36.

32. Spix C, Anderson HR, Schwartz J, et al. Short-term effects of air pollution on hospital admissions of respiratory diseases in Europe: a quantitative summary of APHEA study results. Air Pollution and Health: a European Approach. Arch Environ Health 1998;53:54-64.

33. Cesaroni G, Forastiere F, Agabiti N, et al. Effect of the Italian smoking ban on population rates of acute coronary events. Circulation 2008;117:1183-8.

34. Kent BD, Sulaiman I, Nicholson TT, et al. Acute pulmonary admissions following implementation of a national workplace smoking ban. Chest 2012;142:673-9.

35. Larrauri A, Oliva J. Vigilancia de la Gripe en España. Sistema centinela. Temporada 2005-2006. Boletín Epidemiológico Semanal 2006;14:85-96. http://revista.isciii.es/index.php/bes/article/view/598/ 625 (accessed 15 May 2015).

36. Gorini G. Impact of the Italian smoking ban and comparison with the evaluation of the Scottish ban. Epidemiol Prev 2011;35:4-18.

37. Nagelhout GE, de Vries H, Boudreau C, et al. Comparative impact of smoke-free legislation on smoking cessation in three European countries. Eur J Public Health 2012;22(Suppl 1):4-9.

38. Regidor E, de Mateo S, Ronda E, et al. Heterogeneous trend in smoking prevalence by sex and age group following the implementation of a national smoke-free law. J Epidemiol Community Health 2011;65:702-8.

39. Grupo de Trabajo sobre Tabaquismo de la Sociedad Española de Epidemiología. Evaluacion del impacto de la Ley de medidas sanitarias frente al tabaquismo. Grupo de Trabajo en Tabaquismo de la Sociedad Española de Epidemiología y Ministerio de Sanidad y Política Social. 2009. http://www.seepidemiologia.es/monografia. pdf (accessed 15 May 2015).

40. Huesch MD, Østbye T, Ong MK. Measuring the effect of policy interventions at the population level: some methodological concerns. Health Econ 2012;21:1234-49.

41. Medrano MJ, Alcalde-Cabero E, Ortíz C, et al. Effect of cardiovascular prevention strategies on incident coronary disease hospitalisation rates in Spain; an ecological time series analysis. BMJ Open 2014;4:e004257. 